\title{
A factor in the maintenance of behavior by reinforcement'
}

G. S. REYNOLDS

UNIVERSITY OF CHICAGO

\begin{abstract}
Abstraet
Pecking was maintained on each of two keys by a different, food-associated, conditioned reinforcer, orange illumination of the chamber for the left key and blue for the right key. Then, with pecking prevented, the pigeons were introduced directly into alternating orange and blue illumination and were shocked electrically only during orange. After this procedure, with pecking allowed but without further presentations of either conditioned reinforcer, the rate of pecking on the left of the two keys was selectively decreased.
\end{abstract}

\section{Problem}

If a reinforcing stimulus occasionally follows a response of an appropriately deprived organism, the response tends to recur. Among the classes of variables which determine the rate of occurrence of the response are the character of the response-reinforcer correlation, for example the delay and frequency of reinforcement, and the condition of the organism, for example the magnitude of its relevant deprivation. This report concerns a third class of variables, the characteristics of the reinforcer in the immediate history of the organism.

This variable has been the basis of studies of expectation (e.g., Tolman \& Gleitman, 1949) and of anticipatory goal responses (Miller, 1935). In those studies, animals which had been trained to run to either of two distinctive goal boxes were placed directly into one of the goal boxes and shocked electrically there. After shock in one goal box, the animals ran predominantly to the other goal box. Because the animals had been placed directly in the goal box and shocked, the response of approaching and entering the goal box had not been punished. Rather, the decreasing tendency to approach the goal box associated with shock results from the mere association of the goal box with shock.

The present study shows that this principle also applies to the rate of responding which an animal will emit for one of two conditioned reinforcers.

\section{Subjects}

Four pigeons were maintained at $80 \%$ of their freefeeding weights.

\section{Apparatus}

An operant conditioning chamber for pigeons contained three response keys which could be transilluminated with white light, a magazine beneath the middle key for reinforcing the bird with $3.5 \mathrm{sec}$. of access to mixed grain, provision for general illumination by white, orange, or blue light, and a white masking noise.
Programming and recording equipment were in a separate room.

Electric shocks could be delivered to the pigeon through 10,000 ohms and gold electrodes implanted. bilaterally around their pubis bones (Azrin, 1959). Procedure

The birds were reinforced on two concurrent chained schedules of reinforcement. Initially, the two side keys were lighted. Pecks on the left key were reinforced on a VI 1.5-min. schedule with a conditioned reinforcer, the presentation for $30 \mathrm{sec}$. of orange illumination of the chamber. During this time, both of the side keys were dark, the center key was lighted, and pecks on it were reinforced with food on a VI 1.5-min. schedule. Pecks on the right key when both left and right were lighted were reinforced on a VI $1.5 \mathrm{~min}$. with a 30-sec. presentation of blue illumination of the chamber. During this time, both of the side keys were dark, the center key was illuminated, and pecks on it were reinforced with grain on a VI 3-min. schedule. Daily sessions were about an hour long.

This procedure resulted in the birds' pecking the left key about twice as frequently as they pecked the right key, since pecks on the left eventually led to about twice as frequent presentations of food.

When performance was stable, a session on the following three-part experimental procedure was interposed between every two sessions on the original procedure. (1) Baseline. Extinction (no conditioned reinforcers and no grain) was carried out for $5 \mathrm{~min}$. in the presence of the two lighted keys to establish a baseline. (2) Shock during only one conditioned reinforcer without responses. After a 20-min. wait in its cage, the bird was replaced in the chamber. All three keys were covered with electrical tape. This successfully discouraged all pecking. Three 1-min. periods of orange light were alternated with four 1-min. periods of blue light. During each presentation of orange light, five electric shocks of $250 \mathrm{msec}$. duration were administered to the bird.

The independent variable was the AC voltage imposed across the bird. This was $0,40,50$, or 70 volts, on different experimental days, separated by two days of the original procedure to allow recovery from the effects of the previous shock. Two birds were exposed to all four values, in the order: $0,50,70,40$; two birds received only 0 first and then either 40 or 50 volts. These two birds were shocked in the dark at this voltage in a later session. (3) Effect of shock on 

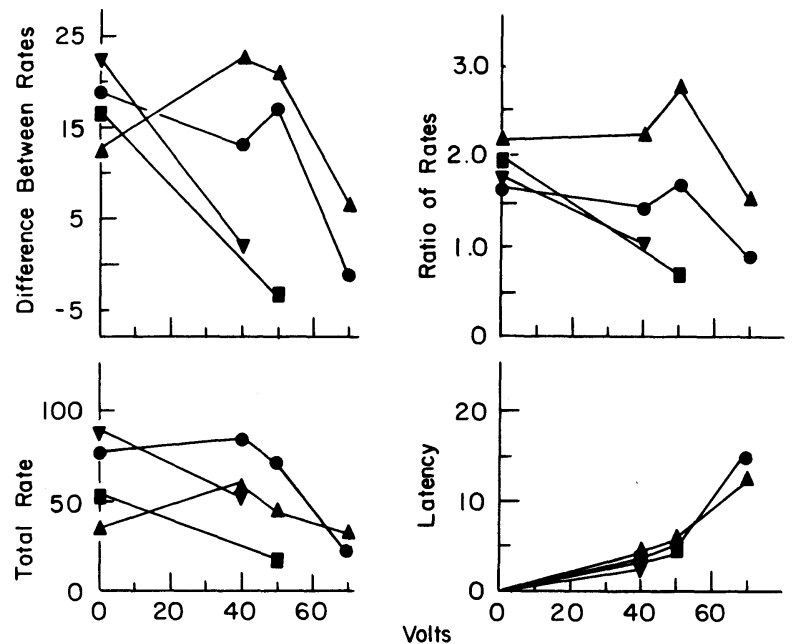

Fig. 1. The difference and ratio between the rates of pecking each of two concurrently available keys, the sum of the two rates, and the latency of the first peck on either key, all as functions of voltage.

baseline. After $20 \mathrm{~min}$. in its cage, changes in the baseline of part 1 were measured during presentation of the two lighted side keys. The dependent variables were the latency between placing the bird in the chamber and the occurrence of the first peck on either key and the rate of responding on each key during the following $10 \mathrm{~min}$. of extinction.

\section{Results and Diseussion}

Figure 1 shows, as a function of voltage, the difference and the ratio between the rates of responding on the two keys as well as the sum of the two rates. Also, the latency is shown in minutes, with the exception that for two birds (upright triangles and squares) the observed latency has been divided by 10 .
One effect of increasing intensities of shock was a decrease in the general tendency to peck either key. The sum of the rates of pecking the left and the right keys is lower at some voltage than with no punishment. For two birds, the decrease occurs at a relatively low voltage. For two birds, a decrease does not occur until a level of 70 volts is reached. Also, the latencies between the start of the session and the first peck increased as the voltage increased.

There was also a selective decrease in the rate of pecking the left key, the response previously reinforced with the orange illumination just previously associated with electric shock. The difference and the ratio between the rates of pecking the left and the right keys decreased. Shocks delivered in the dark did not have this effect, although the total rate of responding decreased slightly.

These results indicate that the rate of occurrence of a response that was previously maintained by a conditioned reinforcer may be decreased by associating the reinforcer with an aversive stimulus, even though the reinforcer is not again presented to the organism. This process may help to account for changes in behavior which seem capricious because the reinforcer is no longer occurring in conjunction with the response.

\section{References}

Azrin, N. H. A technique for delivering shock to pigeons, J. exp. Anal. Behav., 1959, 2, 161-163.

Miller, N. E. A reply to sign-Gestalt or conditioned reflex? Psychol. Rev., 1935, 42, 280-292.

Tolman, E. C., \& Gleitman, H. Studies in learning and motivation. I. Equal reinforcement in both end-boxes, followed by shock in one end-box. J. exp. Psychol., 1949, 39, 810-819.

Note

1. Research supported by grants GB-316 and GB-2541 from the National Science Foundation to the University of Chicago. Reprints may be obtained from the author, Department of Psychology, 5728 South Ellis Avenue, Chicago, Illinois 60637. 